\title{
Determinants of Household Socio-economic Status in an Urban Setting in Ghana
}

\author{
Ernest Mensah Abraham \\ University of Professional Studies, Accra \\ emabraham14@gmail.com \\ DOI//http://dx.doi.org/10.4314/gjds.v13i1.6
}

\begin{abstract}
The study sought to determine the contribution of asset ownership to household socio-economic or wealth status. The study adopted a quantitative research approach to investigate the socioeconomic status of households. A sample of 443 households was selected using a simple random sampling technique, and interviewed. A structured questionnaire was used for the data collection. A Principal Component Analysis was carried out. The results showed that high socio-economic scores tended to correspond with high income status of the households. Thus, households in communities with high infrastructure provision scored high on socio-economic score 1. Socio-economic score 2 was influenced by more informal opportunities. The flexibility of jobs may possibly open the communities with medium to low infrastructure provision to other aspects of socio-economic resources and opportunities which may not be available to the communities with high infrastructure provision. Female headed households were more engaged in self-employed occupations. This explains the level of informality in the access to jobs by female headed households. In general, female headed households were not worse off than male headed households in terms of assets ownership. The relationship between asset ownership and socio-economic status call for evidence based policy interventions.
\end{abstract}

Keywords: Livelihoods, Assets, Accra, Wealth, Score

\section{Introduction}

Households are important units in the developmental agenda of nations all over the world. This is because it is one of the units for measuring the impacts of development interventions. It is the unit where the wealth and poverty conditions of a country are often expressed. Since households have members, it is also the unit for supplying members with the needed resources for survival. Thus, households provide avenues for meeting the basic needs of its members. Households have been defined severally but in general, it is the unit where members depend on one common pool of resources.

The socio-economic status of households in the urban setting is an important phenomenon because it gives an indication of the well-being of the members of the households. Well-being 
here may include the wealth status of the household as well as the degree of poverty that the household is likely to be exposed to. Socio-economic status may be understood from different perspectives. This may include household size, household composition, household livelihoods, and household asset status, among others (GSS, 2010). The measure used to understand the household well-being depends on the purpose of the assessment.

Among others, these measures, including asset status of households, are important when the purpose of the assessment is to improve development interventions that seek to broaden the scope of opportunities available for household members to acquire specific asset categories that would improve the well-being of its members. These assets could be equipment for productive activities; some amount of money in an account, credit worthiness; knowledge, skills, abilities; good relationships with suppliers, social connectedness; land, farm, livestock, among others. These assets can be categorised into five with the aid of the Sustainable Livelihoods Framework [SLF] (DFID, 1999) which has been elaborated below. The SLF helps a researcher to understand the relationship between asset status and wealth or poverty conditions of households. It also shows the possible policy and institutional framework for enhancing households' assets status and thereby reducing the impacts of poverty.

Many studies carried out in the past have emphasized the contribution of livelihoods assets to poverty reduction and well-being of communities (Bury, 2004; Oberhauser \& Yeboah, 2011; Habermas, 1971; Giddens, 1979; Bebbington, 1999). People's assets are actually resources that enables them act when necessary under different circumstances. Possession of assets provides people with the capability to carry out their activities in a more fruitful and meaningful manner (Sen, 1997; Giddens, 1979). Households assets ownership represents the primary building blocks with which households are able to produce, participate in labour markets and have reciprocal exchange with other households (Ellis, 200o). In spite of the diverse studies carried out on household asset ownership, the limited number of single figures to describe household socio-economic status remains a gap that further insight into can facilitate incorporation of development data into development interventions. Thus, the study sought to determine the contribution of asset ownership to household socio-economic or wealth status; calculate household socio-economic scores and examine whether there is any difference between socio-economic status of male and female headed households. 


\section{Theoretical and Conceptual Framework}

The Sustainable Livelihoods Framework [SLF)](Figure 1) is a tool for understanding and analyzing livelihood assets, particularly of the poor.
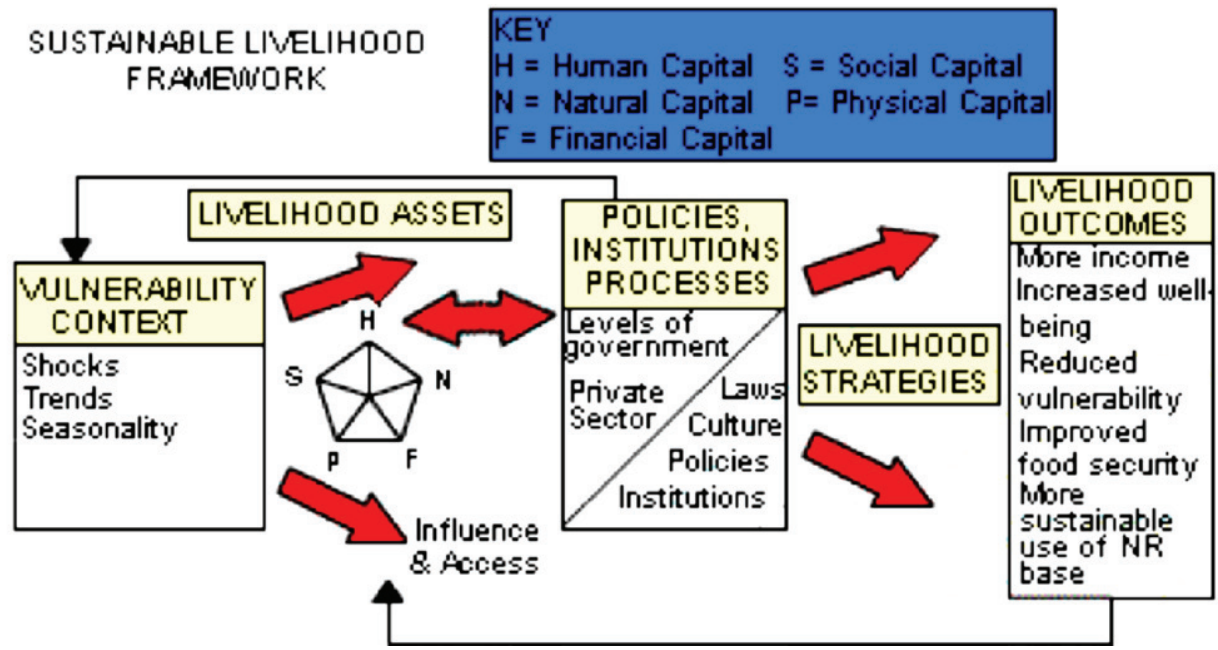

Figure 1: Sustainable Livelihoods Framework

Source: DFID Guidance Sheet (1999)

A definition of livelihood is presented in Carney (1998:4):

"A livelihood comprises the capabilities, assets (including both material and social resources) and activities required for a means of living". The Sustainable Livelihoods Framework provides the conceptual tools for the Sustainable Livelihoods Approaches. The livelihood approach itself builds on the findings of participatory poverty assessments carried out previously (Booth, Holland, Hentschel, Lanjouw \& Herbert, 1998; Hanmer, Pyatt, \& White, 1997). The framework presents livelihoods assets in five different forms: human, social, physical, natural, and financial. Thus, in this study, the five asset types of the SLF were adopted such that the assets identified in the study were categorized in line with the SLF.

Human Capital represents the skills, knowledge, ability to work and good health that together enable people to pursue different livelihood strategies and achieve their objectives. Though not sufficient in itself, it is necessary in achieving positive livelihood outcomes (Scoones, 1998; DFID, 1999). Human capital is particularly relevant to the situation in Accra because it is skills, knowledge and the abilities which enable people to engage in one livelihood or another.

Social capital represents the social resources upon which people draw in pursuit of their livelihood objectives. These are developed through networks and connectedness, either vertical ( patron/client) or horizontal (between individuals with shared interest) 
that increase people's trust and ability to work together and expand their access to wider institutions, be it political or civic bodies (Scoones, 1998). Social capital was investigated in the situation of Accra to identify the extent to which households within communities with common and competing concerns were connected, thus potentially allowing codevelopment of ideas and innovations in livelihoods. Social capital can influence access and use of resources and was therefore important for the investigation.

Natural Capital comprises the natural resource base which provides resources and services (e.g. nutrient recycling, erosion protection, water sources, and livestock in Accra) useful for livelihoods (Richmond, Villiers \& Mkenda, 2003). There is some evidence that providing even relatively small amounts of water to poor people for personal and productive uses can improve their livelihoods ( Lipton \& Litchfield, 2003). Though many factors contribute to low crop productivity for instance, lack of water is important in many cases (Merry, Drechsel, Penning de Vries, \& Sally, 2004).

Physical capital consists of the basic infrastructure (changes to the physical environment which help people to meet their basic needs and be productive; housing, roads, in Accra) and producer goods (tools and equipment that people use to function more productively) needed to support livelihoods (Richmond et al., 2003).

Financial Capital is an embodiment of the financial resources (wages and other incomes, savings, loans, remittances, among others of those in formal and informal livelihoods in the city) that people rely on to achieve their livelihood objectives. It is also noted that these assets are influenced by the existing policy and institutional environment (Nicol, 2000).

From the SLF, there is a relationship between asset ownership and wealth and poverty. The wealth or poverty status of households will determine whether they will achieve their sustainable livelihoods outcome: more income, increased well-being, reduced vulnerability, improved food security, more sustainable use of natural resources, among others (Figure 1). Theoretically, people with high asset status score high on wealth status and low on the poverty status. That is, assuming they are able to respond to vulnerabilities and are aided by the policies and institutions of the country to be able to convert one asset to another in order to achieve their needs. Often various socio-economic indicators are analysed to determine the extent of wealth possessed by a household, an individual or a group. Wealth and poverty are the two sides of a coin. Asset ownership in Accra is varied, depending on several factors. Thus, this study sought to unravel some of these factors. Thus, the gap in knowledge was that often these assets are discussed separately without a good attempt to consider how they relate with one another to define wealth and poverty status of households. Especially, how an aggregate score can be obtained to define the asset status of households. This is where this study comes in to consider the usefulness of carrying out such an analysis and the benefits that it would add to interventions and efforts aimed at helping households to achieve their sustainable livelihood outcomes. The study sought to answer the following research questions: what are the contributions of household asset ownership to wealth or 
socio-economic status of households?; what assets ownership is key in wealth distribution in households? Are there any differences in the socio-economic status of male and female headed households?.

\section{The Hypothesis for the Study}

Ha: There is no significant difference in socio-economic score of male and female headed household.

\section{Methodology}

\section{Study Area}

The study was carried out in Accra, the capital of Ghana. It is a cosmopolitan city with various commercial activities carried out in it. The city can be mapped out into different levels of income and infrastructure provision. In many communities in Accra, often a high income zone is also characterized by good infrastructure provision. This dimension was found to be useful and important in designating the communities as peri-urban, high, medium and low infrastructure provision communities. This is because in some cases one would find low income housing interspersed with high income housing. Thus, designating a community just by income levels may be misleading. However, what is evident and easily verifiable is the level of infrastructure provision. The level of infrastructure provision showed a marked difference between peri-urban, high, medium, and low infrastructure provision communities. The determination of the level of infrastructure provision includes the availability of social infrastructure. As of the start of the study, the city authority had an outdated classification of communities based on income. This had to be modified to enable it to serve the purpose of the study. For the purposes of this study, the following formed the basis of the analysis of assets ownership in the city. Peri-urban communities: this represents the group of communities that lie on the borders of the city, with a cross-section of household incomes; High infrastructure provision communities: these also have high environmental quality and infrastructure provision, these are also high income households in general; Medium infrastructure communities: these are medium environmental quality and infrastructure provision, with medium income households; and Low infrastructure provision communities: Low environmental quality and infrastructure provision, with low income households.

\section{Research Design}

The study adopted a quantitative research approach to investigate the wealth status of households. This is because particular indicators had to be measured. This was also to enable a principal component analysis to be carried out. A survey design was also adopted to enable 
the researcher collect information from a large group of people. The study was also crosssectional as the data was collected within a specific period of time.

\section{Sampling Technique}

The population of the study was all households in the Accra Metropolitan Area. The sampling frame was households from ten communities categorised into four groups located in the city. The four groups were namely, Peri-urban (Abokobi, Pantang), High (Dzorwulu, Kokomlemle, Abelemkpe), Medium (Nima, Alajo), and Low (Abofu, North Industrial Area, Sabong Zongo) infrastructure provision. Infrastructure provision had to do with the level of development of social infrastructure in the communities. The sample size for the study was 443 households (Table 1).

Table 1: Sampling allocation for household interviews [ $\mathrm{N}=443]$

\begin{tabular}{|l|l|}
\hline Community & Sample size \\
\hline Abokobi/Pantang & 40 \\
\hline Agbogba & 42 \\
\hline Abelemkpe & 39 \\
\hline Dzorwulu & 40 \\
\hline Kokomlemle & 43 \\
\hline Nima & 70 \\
\hline Alajo & 42 \\
\hline Abofu & 44 \\
\hline North Industrial & 40 \\
\hline Sabon Zongo & 43 \\
\hline Total & 443 \\
\hline
\end{tabular}

Source: Author's Construct, 2010

The sampling procedure selected was the cluster sampling. Cluster here represent homogeneous groups in the population and in this case the communities. A simple random sampling approach was used to select 443 households.

\section{Instrument for Data Collection}

The structured questionnaire included questions on the ownership or otherwise of these assets: human: possession of health insurance, employment, education; social: political leadership, religious leadership, and membership of occupational association; financial: household member has a bank account, household member in a savings group, accessed credit or loan, water bought at PURC rate; physical: presence or ownership of a tap water connection in residence, flush toilet, other toilet, mains electricity, car, bike, motor bike and Gas stove; and natural assets: ownership of livestock, and ownership of farmland. Other questions included the gender of household head. 


\section{Data Collection and Data Analysis}

The administration of the questionnaire took the following form: Four enumerators administered the questionnaires to households. A member of each household was interviewed. The completed questionnaires from the household survey were first coded and the data input into Statistical Product and Service Solution (SPSS) software. Principal component analysis (PCA) was carried out to assign weights to the assets owned by households. In this case, redundancy means that some of the variables are correlated with one another. Thus, it should be possible to reduce the observed variables into a smaller number of principal components (weights) that will account for most of the variance [differences] in the observed variables (the data from the field).

In this research, the output of PCA is a Table of scores or weights for each variable (Table 2). In general a variable with a positive weight is associated with a higher socio-economic status (SES), and conversely a variable with a negative weight is associated with lower SES. This means that all things being equal, a household with an asset giving a negative score will be ranked lower in terms of SES than a household without such an asset (Vyas \& Kumanayake, 2006).

The PCA works best when asset variables are correlated, but also when the distribution of variables varies across cases. It is the assets that help differentiate between households that are given more weight (McKenzie, 2003). Variables with low standard deviation will carry a low weight from the PCA; for example an asset which all households own or which no household own (that is zero standard deviation) would exhibit no variation between households and would be zero weighted [SES] (Vyas \& Kumanayake, 2006).

Using the first principal component (first set of weights) [Table 2], a dependent variable was then computed for each household (Y) [Socio-economic score] which has a mean equal to zero and a standard deviation equal to one. This dependent variable can be regarded as the 'socioeconomic' score, and the higher the household socio-economic score, the higher the implied SES or wealth of that household. This is in the sense that assets ownership of a household influences the SES. Households with high socio-economic status are perceived as able to afford more of these assets.

The PCA mechanism is such that it provides various sets of weights called principal components to account for the variance in the data. Each set of weight is known as a component by the PCA analysis. In this study, the first and second components (set of weights) were found to be relevant since they accounted for a higher proportion of the variance as compared to the other components and therefore used by the researcher to calculate the socio-economic scores one and two of each household. This is so because particular assets were assigned higher weights in these components than in other components. Mean socio-economic scores one and two for households in the different communities were also calculated. 


\section{Results and Discussion}

The PCA produced two different sets of weights (Table 2) to account for the differences in wealth status of households. The significance of these weights, what they stand for, and how they complement each other are elaborated in this section.

Table 2: Weights as generated by the PCA

\begin{tabular}{|c|c|c|c|}
\hline Number & Asset & Weight 1 & Weight 2 \\
\hline 1 & Health Insurance & .175 & .019 \\
\hline 2 & Household bank Account & .410 & -.069 \\
\hline 3 & household member in savings group & .166 & .188 \\
\hline 4 & Household member accessed credit or loan & .183 & .117 \\
\hline 5 & Ownership of livestock & .024 & .066 \\
\hline 6 & Political leadership & .063 & .114 \\
\hline 7 & Religious leadership & .269 & .041 \\
\hline 8 & Membership of occupational association & .182 & .050 \\
\hline 9 & Tap water connection in residence & .506 & -.241 \\
\hline 10 & Water obtained at PURC rate & .484 & -.292 \\
\hline 11 & House & .365 & -.083 \\
\hline 12 & Flush toilet & .625 & -.230 \\
\hline 13 & Mains electricity & .225 & .022 \\
\hline 14 & Car & .611 & -.069 \\
\hline 15 & Bike & .161 & .206 \\
\hline 16 & Motor bike & .034 & .249 \\
\hline 17 & Gas stove & .537 & -.038 \\
\hline 18 & watch or clock & .450 & .033 \\
\hline 19 & Sewing machine & .363 & .052 \\
\hline 20 & Electric iron & .572 & .333 \\
\hline 21 & Refrigerator & .685 & .316 \\
\hline 22 & Television & .669 & .431 \\
\hline 23 & Radio or tape recorder & .626 & .405 \\
\hline 24 & Video deck & .304 & .316 \\
\hline 25 & DVD player & .596 & .347 \\
\hline 26 & Mobile phone & .511 & .232 \\
\hline 27 & Other toilet & -.109 & -.113 \\
\hline 28 & Bathroom & .300 & -.208 \\
\hline 29 & Single room detached or shared house & -.448 & .245 \\
\hline 30 & Double room self-contained detached or shared & .165 & -.233 \\
\hline 31 & Double room shared or detached & -.021 & .006 \\
\hline 32 & Three or more rooms & .454 & -.067 \\
\hline 33 & Access to public toilet & -.455 & .359 \\
\hline 34 & Formal employment 1 & .342 & -.399 \\
\hline 35 & Informal employment 1 & -.021 & .332 \\
\hline 36 & Informal employment 2 & .029 & .449 \\
\hline 37 & Low education 1 & -.308 & .539 \\
\hline 38 & Low education 2 & -.160 & .575 \\
\hline 39 & Medium education 1 & .295 & -.197 \\
\hline 40 & High education 1 & .417 & -.405 \\
\hline
\end{tabular}

Source: Field data, 2010 
The first set of weights (see Table 2) indicates that physical assets, occupational associations, financial assets, presence of tap water, medium and high levels of education and formal employment are assets with comparatively higher scores than the others and therefore influenced the associated socio-economic scores more. Since the socio-economic score is obtained by multiplying the weight of an asset with the number of any particular asset owned by the household and then summing up the values for all the different assets owned by the households. The first set of weights were used to calculate for socio-economic score 1 for each household (Figure 2). This is in line with the procedure for using PCA (see the methodology). The 'remaining' differences in socio-economic status between the households were accounted for by the second set of weights (uncorrelated with the first set) which were used to calculate the socio-economic score 2 for each household. The PCA generates principal components which are the weights. Each set of weights accounts for a proportion of the variance in the data. Thus, the analysis generated several components until all the variance in the data had been accounted for. Usually in PCA, the first two components are the most significant in terms of the proportion of the variance they explain. Beyond the first two, the rest explain very small proportions of the variance. Thus, the focus on the first two components or set of weights.

The second set of weights indicates that other physical assets - bicycle, motor bike, and livestock [more important in the second set of weights than the first], political leadership, use of public toilets, informal employment, and low educational level are the parameters which contribute most to the 'remaining' differences in socio-economic score between households. Each set of weight emphasizes a particular set of the assets. Mean socioeconomic scores for the first and second sets of weights were calculated for households in each community (Figure 2).

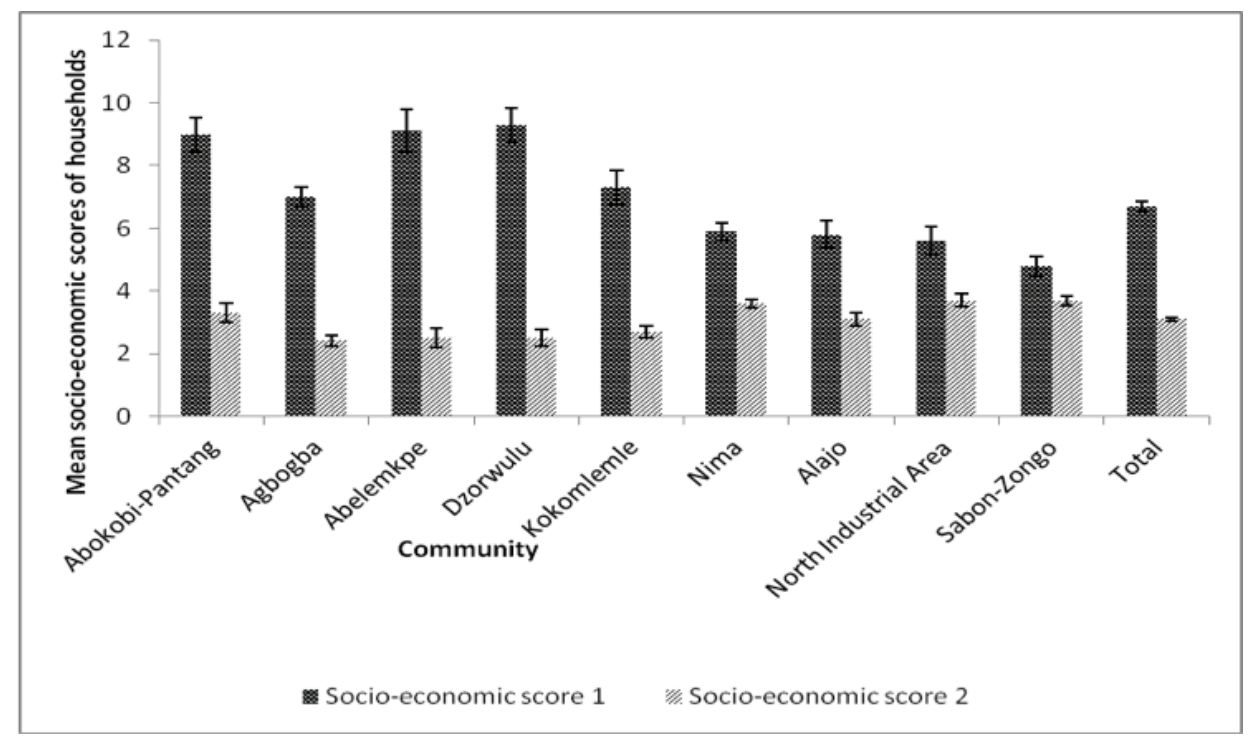

Figure 2: Socio-economic scores of households in the communities 
Source: Field data, 2010

The PCA identified two aspects of socio-economic status clustering (or wealth clustering) occurring at the household level since every household had values for both socio-economic score 1 and 2 (Figure 1). Table 2 shows that the first score relates to socio-economic status of households as determined by more formal employment and high ownership of physical, financial and human assets, as indicated by the weights, whereas the second score relates to the socio-economic status of household to the extent that they benefit from a more flexible access to informal income generating activities (Table 2). Thus, it is observed that households scoring high on socio-economic score 1, scored low on socio-economic score 2 and vice versa, as shown, for example, in the communities with high infrastructure provision, (Figure 2) (Abelemkpe, Dzorwulu, Kokomlemle). This implies that socio-economic status of households is determined by both formal and informal sources of assets. In general, the two forms of wealth clustering are to some extent mutually exclusive, such that households doing well on the more formal opportunities normally will not do well on the informal opportunities and vice versa. This means that every household benefits from these two forms of wealth clustering (every household has some amount of physical and human assets, and some form of income generation). Each component actually represents a particular socio-economic construct. So the weights are assigned in each component to reflect this construct.

\section{Socio-economic Score 1 of Households in Different Communities}

In the high infrastructure provision communities, the mean socio-economic score 1 of households at Abelemkpe $(9.1 \pm 0.69)$ and Dzorwulu $(9.4 \pm 0.54)$ were statistically significantly higher than the mean socio-economic score 1 of households at Kokomlemle $(7.33 \pm 0.55)$ and mean socio-economic score 1 of all the other remaining communities $(\mathrm{P}<0.05)$. This agrees with the mean household incomes (Figure 3) and the mean per capita monthly household incomes (Table 3) observed for Abelemkpe and Dzorwulu. Abelemkpe and Dzorwulu are high income communities as shown in Figure 3 and Table 3. Thus, giving an indication that high socio-economic score is more likely to correspond with high household income status. In fact the SLF indicates that one asset can actually be converted into any one of the five assets presented by the framework. Physical assets for instance can be obtained from financial assets (DFID, 1999). 


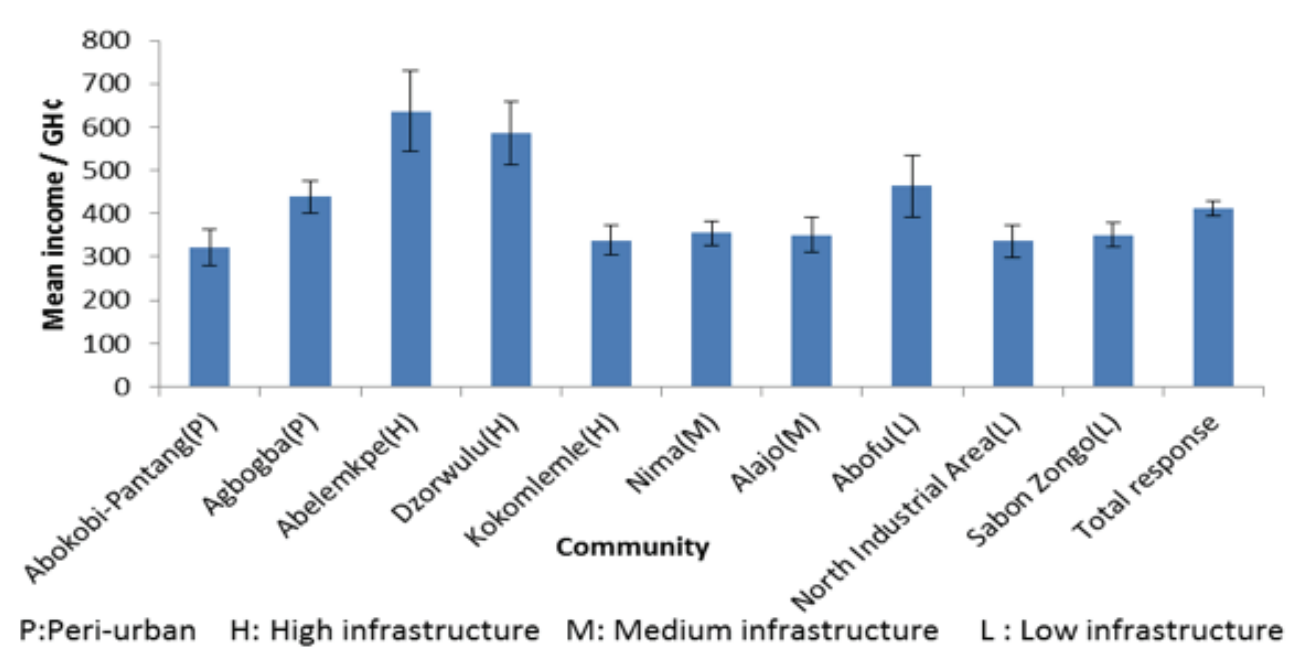

Figure 3: Mean total household income in different communities

(1 USD was equivalent to $\mathrm{GH} \$ 1.50$ in 2010)

Source: Field data, 2010

The mean socio-economic score 1 of households at Kokomlemle (high infrastructure provision) was significantly higher than at Nima, Alajo, North Industrial Area, and Sabon Zongo ( $\mathrm{P}<0.05)$. This agrees with the mean per capita household income (Table 3) which showed households at Kokomlemle as better off than the mean monthly household income showed it to be (Figure 3). This gives an indication that multiple measurements or considerations are important in understanding the socio-economic status of households. This would ensure that the right decisions are made when it comes to development interventions. 
Table 3: Mean per capita monthly household income

\begin{tabular}{|l|l|l|l|}
\hline Location of Respondent [N] & $\begin{array}{l}\text { Mean per capita income } \\
\text { GHథ (USD in brackets) }\end{array}$ & $\begin{array}{l}\text { Std. Deviation } \\
\text { (GHథ) }\end{array}$ & $\begin{array}{l}\text { Std. Error of } \\
\text { Mean (GHథ) }\end{array}$ \\
\hline Abokobi/Pantang & $74.914(50.7)$ & 63.05 & 10.00 \\
\hline Agbogba & $116.99(79)$ & 69.53 & 10.73 \\
\hline Abelemkpe & $108.26(73)$ & 78.59 & 12.58 \\
\hline Dzorwulu & $160.88(109)$ & 138.61 & 21.92 \\
\hline Kokomlemle & $136.27(92)$ & 87.48 & 13.34 \\
\hline Nima & $86.7(58.6)$ & 59.979 & 7.17 \\
\hline Alajo & $102.30(69)$ & 90.77 & 14.01 \\
\hline Abofu & $83.13(56)$ & 54.05 & 8.15 \\
\hline North Industrial Area/ Avenor & $90.10(61)$ & 70.52 & 11.15 \\
\hline Sabon Zongo & $79.50(54)$ & 46.80 & 7.14 \\
\hline Total sample [443] & $102.64(69.4)$ & 81.63 & 3.88 \\
\hline
\end{tabular}

Source: Field data, 2010

For the medium and low infrastructure communities, where medium represents conditions between high and low infrastructure (see study area above) the mean socio-economic score 1 of households at Abofu $(7.5 \pm 0.43)$ was statistically significantly higher than households in Nima (5.94 \pm 0.26$)$ and Alajo $(5.86+0.43)$. Mean socio-economic score 1 of households at Abofu was also significantly higher than mean socio-economic score 1 of households at North Industrial Area and Sabon Zongo ( $\mathrm{P}<0.05)$. This also agrees with the mean total household income for Abofu (Figure 3) but does not agree with the mean monthly per capita household income which showed Abofu as being worse off than the income levels projects it to be (Table 3). Thus, in general, households with high socio-economic scores tended to also have high household income. High household income enables households to obtain household assets for their livelihoods. The situation in Abofu also shows that income alone is not adequate in understanding the state of household. This strengthens the need for development interventions to adopt a multi-approach. This mean that different indicators which measure household welfare should be considered. Various investigations in the past have also confirmed the contribution of livelihoods assets to poverty reduction and wellbeing of communities (Bury, 2004; Oberhauser \& Yeboah, 2011; Habermas, 1971; Giddens, 1979; Bebbington, 1999). 


\section{Socio-economic Score 2}

The mean socio-economic score 2 at Abofu $(3.1 \pm 0.22)$ was significantly higher than the mean socio-economic score 2 at Dzorwulu ( $\mathrm{P}<0.05)$. Since Abofu had a low mean per capita monthly income, this is consistent. In the medium infrastructure communities, the mean socio-economic score 2 at Nima (3.6 \pm 0.14$)$ and Sabon Zongo ( $3.72 \pm 0.15)$ were significantly higher than mean socio-economic score 2 at Abelemkpe, Dzorwulu, Kokomlemle, and Abofu $(\mathrm{P}<0.05)$. This agrees with the fact that both Nima and Sabon Zongo scored lower socioeconomic score 1. Furthermore, the mean socio-economic score 2 at Alajo (3.15 \pm 0.19$)$ was significantly higher than at Abelemkpe and Dzorwulu $(\mathrm{P}<0.05)$. This is consistent with the fact that, Alajo recorded a lower socio-economic score 1 (Figure 2). In general, since the two dimensions of socio-economic status are mutually exclusive, households with high socioeconomic score 1 tended to have low socio-economic score 2. This indicates that informal sources of wealth are available for those without formal sources. This enables every household to do something for a living in order to achieve their livelihoods outcome. This reflects what happens in an urban setting where various opportunities are available for household members to explore. The extent to which households can access these assets will depend on the conditions which govern local transactions.

\section{Differences between Male and Female headed Households}

In relation to socio-economic score 1 , male headed households scored higher in peri-urban and in communities with medium infrastructure provision with virtually no difference between male and female headed households in the communities with low infrastructure provision (Figure 4).

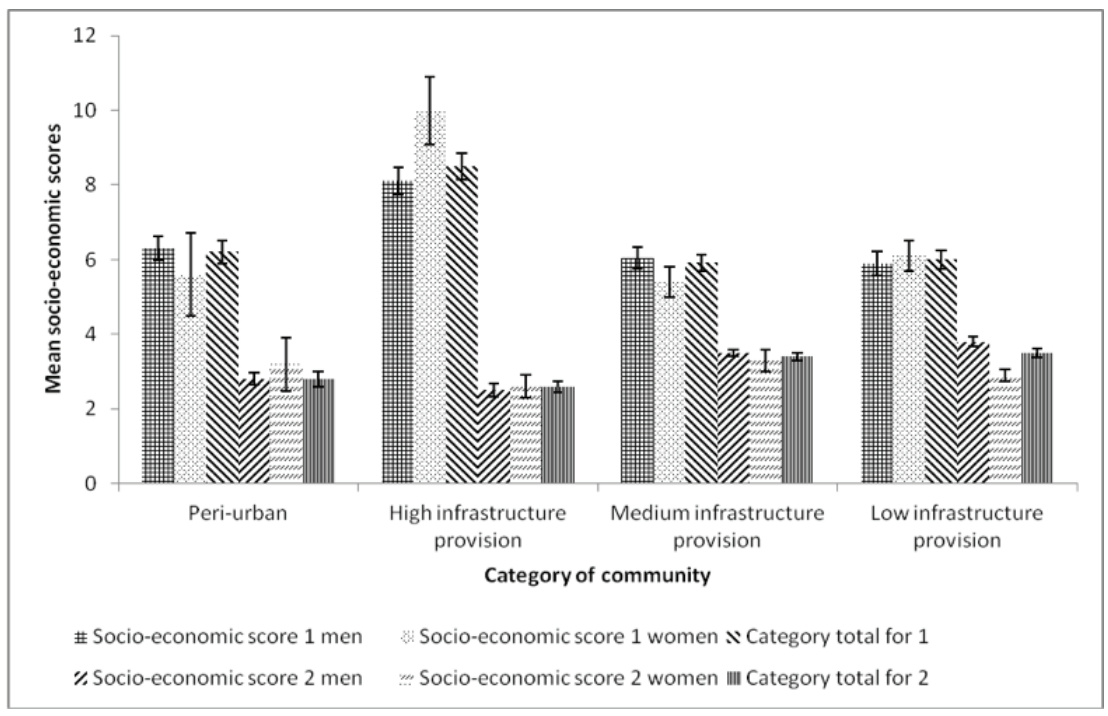

Figure 4: Mean socio-economic scores of male and female headed households in different categories of communities Source: Field data, 2010 
Female headed households scored significantly higher than male headed households in the communities with high infrastructure provision $(\mathrm{P}<0.05)$. This is not consistent with the mean total monthly household income of the female headed households since it was lower than the male headed household (Table 4). This shows that female headed households were ahead in terms of socio-economic status and therefore in terms of non-monetary assets ownership, they were ahead of the male headed household. This reiterates the point that poverty assessments must go beyond just a definition based on monetary considerations.

Table 4: Mean monthly household income of male and female headed households

\begin{tabular}{|c|c|c|c|c|}
\hline $\begin{array}{l}\text { Category of } \\
\text { community }\end{array}$ & $\begin{array}{l}\text { Gender of household } \\
\text { head }\end{array}$ & $\begin{array}{l}\text { Mean total monthly } \\
\text { household income } \mathrm{GH} \phi \\
\text { [USD in brackets] }\end{array}$ & $\mathrm{SD}(\mathrm{GH} \Phi)$ & $\mathrm{SE}(\mathrm{GH} \phi)$ \\
\hline \multirow{3}{*}{$\begin{array}{l}\text { Peri-urban } \\
{[\mathrm{n}=82]}\end{array}$} & Men [73] & $407.41(275.27)$ & 258.5 & 30.25 \\
\hline & Women [8] & $158.75(107.3)$ & $129 \cdot 9$ & 1.02 \\
\hline & Total [81] & $382.85(273.5)$ & 259.94 & 28.77 \\
\hline \multirow{3}{*}{$\begin{array}{l}\text { High infrastructure } \\
\text { provision }[\mathrm{n}=122]\end{array}$} & Men [94] & $558.37(377 \cdot 3)$ & 493.95 & 50.94 \\
\hline & Women [27] & $361.18(244)$ & 242.86 & 46.74 \\
\hline & Total [ 121] & $514.00(347.3)$ & 456.8 & 41.52 \\
\hline \multirow{3}{*}{$\begin{array}{l}\text { Medium } \\
\text { infrastructure } \\
\text { provision } \\
{[\mathrm{n}=112]}\end{array}$} & Men [89] & $395.75(267.4)$ & 247.18 & 26.2 \\
\hline & Women [22] & $180.50(122)$ & 112.01 & 28.88 \\
\hline & Total [111] & $353.04(238.5)$ & 242.3 & 23 \\
\hline \multirow{3}{*}{$\begin{array}{l}\text { Low infrastructure } \\
\text { provision } \\
{[\mathrm{n}=127]}\end{array}$} & Men [ 79] & $445.94(301.3)$ & 371.95 & 41.85 \\
\hline & Women [44] & $276.66(192.1)$ & 160.52 & 24.2 \\
\hline & Total [ 123] & $385.38(260.4)$ & 322.76 & 29.1 \\
\hline \multirow{3}{*}{$\begin{array}{l}\text { Total sample } \\
{[n=443]}\end{array}$} & Men [335 ] & $455.70(308)$ & 367.7 & 20.1 \\
\hline & Women [ 101 ] & $268.90(182.7)$ & 187.45 & 18.65 \\
\hline & Total [ 436] & $412.50(278.7)$ & 343.7 & 16.5 \\
\hline
\end{tabular}

Source: Field data, 2010

In relation to socio-economic score 2, male headed households scored higher in communities with medium and low infrastructure provision (significantly higher in the latter) $(\mathrm{P}<0.05)$. Female headed households scored higher in peri-urban and communities with high infrastructure provision. However, these differences were not significant ( $>0.05)$. In general, in terms of urban and peri-urban assets ownership, apart from the communities with high infrastructure provision (in relation to socio-economic score 1; where female headed households were significantly better off) and communities with low infrastructure provision (in relation to socio-economic score 2; where male headed households were 
significantly better off), the evidence in the study did not indicate that female headed households were significantly worse off than male headed households in terms of household asset ownership in the remaining category of communities. This could be explained by the fact that both male and female headed households are presented with similar opportunities to go about their livelihood activities. Urbanization may come with both opportunities and challenges. Perhaps in respect of asset ownership, gender differences are not that important because of the lack of specific formal or informal arrangements to restrain any particular gender from engaging in any livelihoods activities.

Thus, it is important to observe on Figure 5 that households in the communities with high infrastructure provision tend to be favoured by more settled jobs (formal) with comparatively reduced reliance on informal opportunities as compared to the communities with medium and low infrastructure provision. Thus, households in communities with high infrastructure provision scored high on socio-economic score 1. The flexibility of jobs (high degree of informality) [Figure 5] may possibly open the communities with medium to low infrastructure provision to other aspects of socio-economic resources and opportunities which may not be available to the communities with high infrastructure provision.

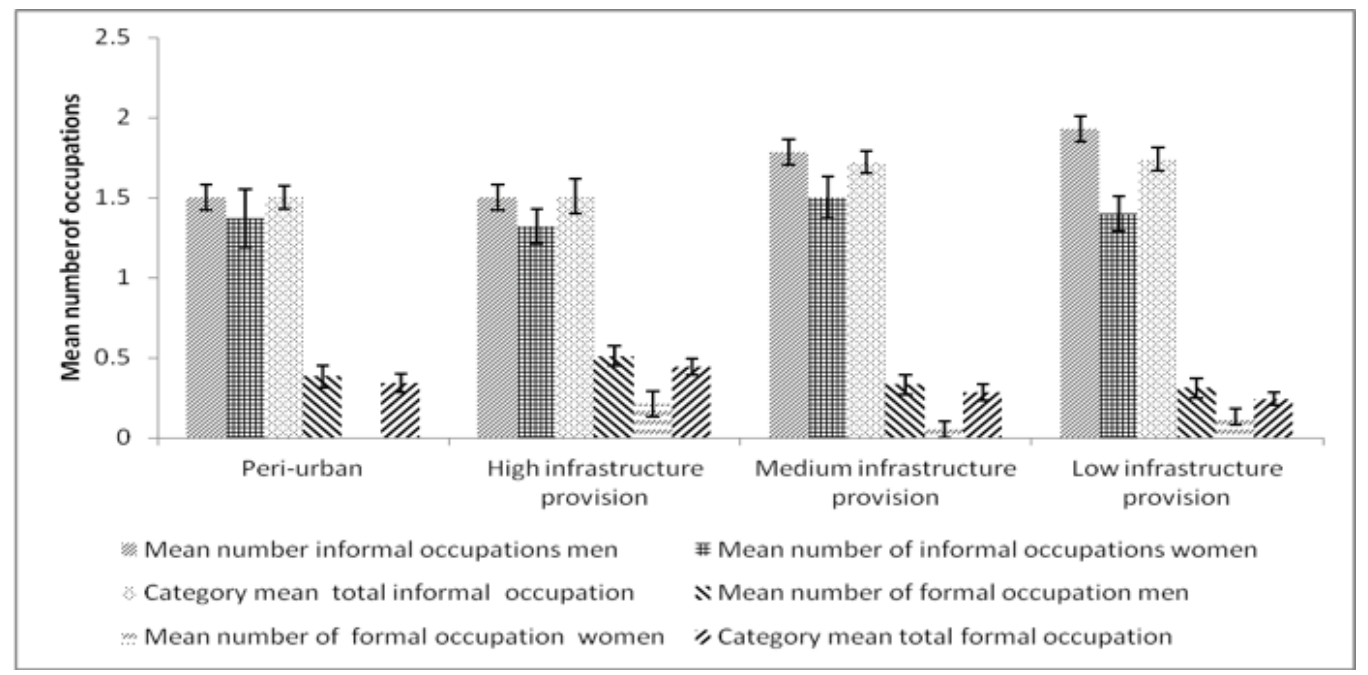

Figure 5: Mean total number of formal and informal occupations in male and female headed household

Though informal occupations are important in all categories of communities, they are more important in the communities with medium and low infrastructure provision. The mean total number of people engaged in formal occupations in male headed households of high, medium, and low infrastructure provision communities were significantly higher than those of female headed household $(\mathrm{P}<0.05)$. Thus, female headed households were more engaged in self-employed occupations. This explains the level of informality in the access to jobs by female headed households. Mitlin (2003) stresses that poor people's assets have to be developed to improve the effectiveness of development interventions. In other words, 
development interventions which do not enhance livelihood assets are incomplete. Mitlin emphasizes that successful interventions should consider a set of issues that are mutually re-inforcing.

\section{Conclusion and Recommendations}

The study has shown that no matter the socio-economic status of a household, it possesses one asset or another to support its survival or livelihood. Asset ownership is not restricted only to tangible (material) ones but also to the intangible (non-material) ones such as access to education, job, membership of associations and health insurance.This implies that efforts to improve households' wealth status and reduce poverty should adopt a multiapproach with emphasis on the five components of the sustainable livelihoods framework. The comparison between income and asset status of household makes asset ownership an important analysis for understanding the socio-economic status of households. The term assets refer to the possession of households which allows them to do various activities to meet their needs. Household assets are significant because they frame the resources available to the households. Often household needs are time bound and therefore possession of the appropriate assets at the opportune time will ensure that resources are supplied at the right time.

Asset ownership determines the wealth or socio-economic status of households. The inability of a household to obtain these assets on time suggests that they may be caught up in an incident of poverty. In effect, households may be empowered or disempowered from the presence or absence of assets respectively. Assets are significant contributors to household survival because both productive and reproductive abilities and potential of households are driven by these assets. Whereas it is relatively simpler for differences in income levels of male and female headed households in the urban setting to be observed, it is not the same with most of the other assets because both men and women have a wide range of opportunities for their livelihoods.

This implies that development interventions can benefit both men and women if it creates ample opportunities for them to expand their assets. This calls for putting in place appropriate regulatory and institutional framework that will allow one asset to be converted to another. The asset analysis also showed those that are making important contributions to the household socio-economic score or status, and therefore these can be reinforced in development interventions. If assets are projected as contributing little to the socio-economic status of a household, though it is important, such as education or healthcare, then it becomes an important avenue for development interventions. It is therefore recommended that assessment of wealth status of households should not adopt only one approach but a multi-approach that can bring out the different aspects of wealth in the communities. It is also recommended that more indicators of the intangible aspects of wealth of households should be explored and developed so that they can be factored into future analysis. 


\section{Acknowledgment}

The author is grateful to the University of Greenwich, International Water Management Institute and the EU funded SWITCH project for funding the research that led to this paper.

\section{References}

Bebbington, A. (1999). Capitals and capabilities: A framework for analyzing peasant viability, rural livelihoods and poverty. World Development, 27(12), pp. 2021-2044.

Booth, D., Holland, J., Hentschel, J., Lanjouw, P. and Herbet, A. (1998). Participative and combined methods in : Renewing the agenda. London: Department for International Development.

Bury, J. (2004). Livelihoods in transition: transnational gold mining operations and local changes in Cajamarca, Peru. Journal, 170 (1), pp. 78-91.

Carney, D. (1998). Implementing the Sustainable Rural Livelihoods Approach. In Carney, D. (ed). Sustainable Rural Livelihoods: What Contributions can we make? Papers Presented at the Department for International Development's Natural Resources Adviser's Conference. London: DFID, pp. 3-23.

Department for International Development [DFID] (1999). Sustainable livelihoods guidance sheets. London: DFID.

Ellis, F. (2000). Rural livelihoods and diversity in developing countries. Oxford, UK: Oxford University Press.

Giddens, A. (1979). Contemporary problems in social theory: Action, structure and contradiction in Social Analysis. London: Macmillan.

Ghana Statistical Service [GSS] (2013).2010 Population and housing census. National analytical report.

Habermas, J. (1971). Knowledge and human interests. Boston: Beacon Press.

Hanmer, L., Pyatt, G., and White, H. (1997). Poverty in Sub-Saharan Africa. What can we learn from the World Bank's Poverty Assessment? The Hague: ISS.

Lipton, M. and Litchfield, J. (2003). Preliminary review of the impact of irrigation on poverty, with special emphasis on Asia. Rome: Food and Agriculture Organization (AGL/ MISC/34/2003).

McKenzie, D.J. (2003). Measure inequality with asset indicators. BREAD Working Paper No. 042. Cambridge, MA: Bureau for Research and Economic Analysis of Development, Center for International Development, Harvard University. 
Merry, D.J., Drechsel, P., Penning de Vries, F.W.T. and Sally, H. (2004). Integrating 'livelihoods' into Integrated Water Resources Management: Taking the integration paradigm to its logical next step for developing Countries. Pretoria: International Water Management Institute.

Mitlin, D. (2003). Addressing urban poverty through strengthening assets. Habitat International, 27, pp. 393-406.

Nicol, A. (2000). Adopting a sustainable livelihoods approach to water: Implications for policy and practice. Working Paper 133. London: Overseas Development Institute.

Oberhauser, A.M. and Yeboah, M.A. (2011). Heavy burdens: Gendered livelihood strategies of porters in Accra, Ghana. Singapore Journal of Tropical Geography, 32, pp. 22-37.

Richmond, M.D., De villiers, A. and Mkenda, A.F. (2003). Livelihoods assets required for an East Africa FADs programme. Final Technical Report. Fisheries Science Management Programme (FMSP). Project R8249. Dar es Salaam: Samanki Consultants Limited.

Sen, A. (1997). Editorial: Human capital and human capability. World Development, 25 (12), pp. 1959-1961.

Scoones, I. (1998). Sustainable rural livelihoods: a framework for analysis. IDS Working Paper 72.

Vyas, s. and Kumaranayake, L. (2006). How to do (or not to do)... : Constructing Socio-economic status indices: How to Use Principal Component Analysis. Oxford University Press in association with The London School of Hygiene and Tropical Medicine, pp. 459-468. 